\title{
Nitrofurantoin Monohydrate
}

National Cancer Institute

\section{Source}

National Cancer Institute. Nitrofurantoin Monohydrate. NCI Thesaurus. Code C77144.

A monohydrate form of nitrofurantoin, a synthetic derivative of imidazolidinedione

(hydantoin) that inhibits bacterial DNA, RNA, and cell wall protein synthesis. 